\title{
CONTROVERSY
}

\section{Adrenaline syringes are vastly over prescribed}

\author{
D J Unsworth
}

Allergy is being seen more and more commonly. A recent review of accident and emergency admissions in England reported 415 anaphylactic cases (adults and children) from 100000 referrals in $1991 / 92$, but 876 in $1994 / 95 .{ }^{1}$ Death following anaphylaxis is most feared but fortunately remains a very rare event, currently estimated at less than one case per year per million of the UK population. ${ }^{2}$ There is always the instinct that these fatal incidents could and indeed should have been avoided or prevented, especially in children. A widely quoted North American study of 13 children and adolescents following fatal or near fatal food related anaphylaxis, ${ }^{3}$ concluded that "epinephrine should be prescribed and kept available for all children and adolescents with IgE mediated food allergies". Applied literally, that is a huge number of cases. A telephone survey estimated a $1 \%$ prevalence for peanut allergy alone in the United States. ${ }^{4}$ Detailed review of data referred to above ${ }^{3}$ reveals that adrenaline had been prescribed for three of the six fatal cases of food related anaphylaxis and three of the seven non-fatal cases, but was only actually used in the community setting by one case (a survivor). Also, the authors noted that "four of the children who received epinephrine before severe symptoms developed, became progressively sicker and eventually required intubation". Similar cases where adrenaline administration failed to save lives were reported by Pumphrey. ${ }^{2} \mathrm{~A}$ single dose of adrenaline may prove insufficient, raising the question of how many syringes to prescribe for each case. More than 100000 adrenaline syringes are currently available in the community in the UK, many in a paediatric context.

However, there is no clear evidence that the recent more liberal community prescribing of adrenaline syringes has saved lives significantly on a population basis. Pumphrey's anaphylaxis register data is striking. Only one quarter of all 165 anaphylactic deaths (adults and children) recorded between 1992 and 1998 were food related, and no case was recorded in a child aged less than 13 years. Iatrogenic (majority being drug related) causes were identified in $50 \%$ of cases. Adrenaline overdose, often by the intravenous route, was deemed to be the

Southmead Hospital, Westbury-on-Trym, Bristol BS10 5NB, UK D J Unsworth

Correspondence to:

Accepted for publication two children.

Adrenaline-risk/benefit considerations Adrenaline is a powerful drug, with side effects including fatal cardiac arrhythmias, pulmonary oedema, and cerebral haemorrhage. ${ }^{256}$ Risks are higher in recipients with relatively common arteriopathic conditions such as hypertension and diabetes mellitus. ${ }^{5}$ The more widely adrenaline is prescribed and used, the more frequently will side effects be reported. All these points become more alarming when adrenaline is prescribed to non-medical individuals, sometimes with little or no explicit training, especially in relation to instructions on when to use adrenaline and when not to use it. Comprehensive and helpful published advice on patient training is available, ${ }^{7}$ but compliance is poor. Twenty per cent of families fail to carry adrenaline with them outside the house. ${ }^{8}$ Many others have an imperfect understanding of when and/ or how to use adrenaline. Fifty per cent of those prescribed adrenaline either do not have it with them, carry an out of date prescription, or use it inappropriately. ${ }^{8}$ When adrenaline is carried, there is a risk of excessive patient confidence, perhaps resulting in delayed arrival at hospital.

\section{Adrenaline syringes-indications}

Some consensus exists. It seems reasonable to prescribe adrenaline (assuming full patient/ family training beforehand) in cases where there has been a previous life threatening allergic reaction. Outcome may be worse in cases with uncontrolled asthma, and anaphylaxis in children especially can be mistaken for asthma. ${ }^{2}$ That, however, promotes an argument in favour of focusing efforts towards improved asthma control rather than automatic adrenaline provision. Other cases are far less clear cut. For example, a child with cat allergy severe enough to require admission for asthma and hypoxia would probably not be given an adrenaline syringe to take home. By contrast, a peanut sensitive child reporting a single episode of mild contact urticaria confined to the hands, many years ago, just might be provided with adrenaline on demand, despite having been entirely well when simply avoiding nuts. Whether the latter case merits adrenaline can be debated. On the one hand, it is theoretically possible that future exposure to peanut could provoke a far more serious, potentially life threatening reaction. Conversely, although nut allergy is common, fatal anaphylaxis is exceedingly uncommon, especially in children. ${ }^{2}$

\section{Diagnosis of IgE mediated allergy}

Good up to date data relating to the positive and negative predictive values for allergy tests currently in use is lacking. In a recent commu- 
nity survey, ${ }^{10} 50 \%$ of skin prick test positive infants could eat nuts without ill effect. It seems sensible to restrict tests to individuals who give a convincing clinical history of hypersensitivity, otherwise the risk of "false positive" tests increases. Prescription of adrenaline without a clear clinical history suggestive of genuine type 1 hypersensitivity is ill advised. There is no evidence that specific IgE antibody titre correlates with risk. ${ }^{9}$

\section{Conclusion}

Adrenaline is commonly used as a first line drug in life threatening allergy. ${ }^{11-13}$ Inappropriate use needs to be avoided, however, in view of potentially serious side effects. Community use should be much more restricted with increased involvement and reliance on trained medical staff. The case in favour of the current trend towards prescribing adrenaline more and more widely to the lay public has not been justified. Fatalities directly attributable to adrenaline are a sobering reminder of the risks. ${ }^{2}{ }^{6}$ In our collective enthusiasm to help protect the patient, we have perhaps forgotten the risks, especially in children. It is time to review just who does merit a community adrenaline syringe.
1 Sheikh A, Alves B. Hospital admissions for acute anaphylaxis: time trend study. $B M F$ 2000;320:1441.

2 Pumphrey RSH. Lessons for managementof anaphylaxis from a study of fatal reactions. Clin Exp Allergy 2000;30: 1144-50.

3 Sampson HA, Mendelson L, Rosen JP. Fatal and near-fatal anaphylactic reactions to food in children and adolescents. $N$ Engl f Med 1992;327:380-4.

4 Scherer SH, Munoz-Furlong A, Burks AW, Sampson HA. Prevalence of peanut and tree nut allergy in the US determined by a random digit telephone survey. $\mathcal{F}$ Allergy Clin Immunol 1999;103:559-62.

5 British National Formulary 39. 2000:154-6.

6 Horowitz BZ, Jadallah S, Derlet RW. Fatal intracranial bleeding associated with prehospital use of epinephrine. Ann Emerg Med 1996;28:725-7.

7 Vickers DW, Maynard L, Ewan PW. Management of children with potential anaphylactic reactions in the community: a training package and proposal for good practice. Clin Exp Allergy 1997;27:898-903.

8 Scherer SH, Forman JA, Forman MD, Noone SA. Use assessment of self administered epinephrine among food allergic children and paediatricians. Paediatrics 2000;105: 359-62.

9 Ewan PW. Clinical study of peanut and nut alergy in 62 consecutive patients: new features and associations. BMF 1996;312:1074-8.

10 Tariq SM, Stevens M, Matthews S, et al. Cohort study of peanut and tree nut sensitisation by age of 4 years. BMF 996;313:514-17.

11 Brown AF. Therapeutic controversies in the management of anaphylaxis. F Accid Emerg Med 1998;15:89-95.

12 Project Team of the Resuscitation Council (UK). Emergency medical treatment of anaphylactic reactions. 7 Accid Emerg Med 1999;16:243-7.

13 Patel L, Ravidan FS, David TJ. Management of anaphylactic reactions to food. Arch Dis Child 1994;71:370-5. 